\title{
Molecular cloning and expression analysis of a C-type lectin in the rock bream, Oplegnathus fasciatus
}

\author{
Mun Gyeong Kwon*, Ju Won Kim, Myoung Ae Park*, Jee Youn Hwang*, Hyung Jun Park and Chan Il Park ${ }^{\dagger}$ \\ Department of Marine Biology \& Aquaculture, Institute of Marine Industry, Gyeongsang National University, 455, Tongyeong, \\ 650-160, Korea
}

*Pathology Division, National Fisheries Research and Development Institute, Busan 619-900, Korea

C-type lectins are crucial for pathogen recognition, innate immunity, and cell-cell interactions. In this study, a C-type lectin gene was cloned from the rock bream. The full-length RbCTL cDNA was 729 bp with a 429 bp ORF encoding a 164-residue protein. The deduced amino acid sequence of RbCTL had all of the conserved features crucial for its fundamental structure, including the four cysteine residues involved in sulfide bridge formation and potential $\mathrm{Ca}^{2}+$ /carbohydrate-binding sites. RbCTL contains a signal peptide one single carbohydrate recognition domain. It showed $29.4 \%$ similarity to the C-type lectin of rainbow trout. RbCTL mRNA was predominately expressed in gill and head-kidney tissue and expressed less in peripheral blood leukocytes, trunk-kidney, spleen, liver, intestine and muscle. Expression of RbCTL was differentially upregulated in rock bream stimulated with LPS, Con A/PMA and poly I:C.

Key words : Rock bream, C-type lectin, PBLs, LPS, Con A/PMA, poly I:C

In animals, innate constitutes the first defense against microbial invasion based on pattern recognition. The ability of host humoral - or cell-associated lectins to recognize exposed carbohydrates on the cell surfaces of potential pathogens considered a primary role for pattern recognition molecules in innate immunity (McGreal et al., 2004). Calcium-dependent (C-type) lectins are a major group of pattern-recognition receptors (PRRs) with one or more characteristic carbohydrate recognition domains (CRDs), that possibly mediate pathogen recognition and are important vertebrate and invertebrate innate immunity due to their ability to bind

$\dagger$ Corresponding author: Chan Il Park

TEL : +82-55-772-9153 FAX: +82-55-772-9159

E-mail : vinus96@hanmail.net specific carbohydrates on microbe surfaces in a $\mathrm{Ca}^{2+}$-dependent manner (Homeskov et al., 2003; Vasta et al., 2004; Fujita et al., 2004).

Lectins are multivalent carbohydrate-binding proteins that function as important PRRs. According to their distinct structures and functions, lectins are classified as calnexin C-, L-, P-, I-, R- and S- types (Janeway and Medzhitov, 2002). The C-type lectin family has been well-studied in vertebrates and invertebrates. All C-type lectins share the same structural features including CRD sequences, disulfiide-bond positions, and calcium binding sites (Drickamer, 1999).

In fish, C-type lectins have been identified in the carp (Cyprinus carpio) (Fujiki et al., 2001), rainbow trout (Oncorhynchus mykiss) (Zhang et al., 2000) and 
eel (Anguilla japonica) (Tasumi et al., 2002). Lectins interacting with yeast and fish bacterial pathogens have also been functionally characterized in the conger eel (Conger myriaster) (Tsutsui et al., 2007) and coho salmon (Oncorhynchus kisutch) (Yousif et al., 1994). Lectins that bind to specific sugars such as mannose (Ottiner et al., 1999; Konstantina and Ioannis, 2006; Ourth et al., 2007), fucose (Honda et al., 2000), rhamnose (Okamoto et al., 2005) and galactose (Vitved et al., 2000) have also been isolated and characterized in fish.

The rock bream, Oplegnathus fasciatus, is one of the most economically important fisheries resources in Korea. It habits the Pacific Ocean, including southern parts of the Korean Peninsula, Japan, Taiwan, and Hawaii. It's infrequent compared with other commercially important fishes in Korea. Red sea bream iridovirus (RSIV) disease is the major cause of rock bream mass mortality in Korea (Oh et al., 2007).

In this study, we identified a novel C-type lectin from $O$. fasciatus. C-type lectin was cloned from a constructed cDNA library of rock bream. The cloning and sequencing of the RbCTL, multiple alignment and phylogenetic analysis of the deduced amino acids, tissue distribution and mRNA expression pattern of the RbCTL was investigated.

\section{Materials and methods}

\section{Cloning and sequencing rock bream RbCTL cDNA}

The RbCTL cDNA was identified in the analysis of expressed sequence tags (ESTs) of rock bream liver that were stimulated with the LPS cDNA library (Kim et al., 2010). The similarity analyses of the nucleotide and protein sequences were conducted using the program BLAST at the US National Center for Biotechnology Information (NCBI http://blast.ncbi.nlm.nih.gov/Blast.cgi). The determined nucleotide and deduced amino acid sequences and multiple sequence alignments were analysed with GENETYX ver. 8.0 (SDC Software Development Co., Ltd., Tokyo, Japan). The signal peptide was predicted using the online SignalP 3.0 programme (http://www.cbs.dtu.dk/services/SignalP/) and domain identification was analysed with the PROSITE and SMART programmes (http://smart.embl- heidelberg.de/).

2. Fish, tissues sampling, and expression analysis Rock bream (approximately 200 g) were purchased from TongYeong fish market in Korea. The fish were maintained in a laboratory recirculating seawater system at $20^{\circ} \mathrm{C}$ for domestication. They were anesthetized using benzocaine (Sigma-Aldrich, Co, USA). For PBL sampling, a heparin-treated syringe was used to collect blood from a tail unit vein. The peripheral blood leukocytes (PBLs) were prepared as described previously (Park et al., 2003). The head-kidney, trunk-kidney, spleen, liver, intestine, gill and muscle tissue samples were dissected from the fish.

Total RNA was extracted from rock bream PBLs, head-kidney, trunk-kidney, spleen, liver, intestine, gill and muscle tissue using the TRIzol reagent (Invitrogen, USA). Total RNA was treated with Recombinant DNase I - RNase free (TaKaRa, Japan) to remove DNA. To synthesize cDNA by reverse transcription, $2 \mu \mathrm{g}$ total RNA, oligo dT primer and dNTP mixture, RNase free $\mathrm{dH}_{2} \mathrm{O}$ were reacted for $5 \mathrm{~min}$ at $65^{\circ} \mathrm{C}$ and immediately 
placed on ice for $5 \mathrm{~min}$, then placed in $5 \times$ Primescript buffer, with RNase inhibitor, PrimeScript RTase, RNase free $\mathrm{dH}_{2} \mathrm{O}$ mixture and reacted for $1 \mathrm{~h}$ at $42^{\circ} \mathrm{C}$ and $5 \mathrm{~min}$ at $95^{\circ} \mathrm{C}$.

Peripheral blood leukocytes were collected from one rock bream and stimulated with LPS $(500 \mu \mathrm{g} / \mathrm{mL})$, Con A $(70 \mu \mathrm{g} / \mathrm{mL}) /$ PMA $(0.35 \mu \mathrm{g} / \mathrm{mL})$ or poly I:C $(5 \mu \mathrm{g} / \mathrm{mL})$ as previously described by Park et al.(2003).

The expression in different rock bream tissue was investigated by quantitative real-time PCR using the primers Rb-CTL 3-F and Rb-CTL 3-R. B-Actin was amplified with specific forward and reverse primers (Table 1). The quantitative real-time RT-PCR was carried out in a $25 \mu$ reaction volume containing $12.5 \mu \mathrm{l} 2 \times$ SYBR Green Master Mix (Takara, Kyoto, Japan), $1.0 \mu \mathrm{l}$ cDNAs, each primer $(10 \mathrm{pmol} / \mu \mathrm{l})$, and $9.5 \mu \mathrm{l}$ PCR-grade water. Thermal cycling and fluorescence detection were performed using the Thermal Cycler DICE Real-Time System (Takara, Kyoto, Japan). Amplification was performed by initial denaturation at $94^{\circ} \mathrm{C}$ for $2 \mathrm{~min}$ followed by 30 cycles of $94^{\circ} \mathrm{C}$ for $30 \mathrm{~s}, 58^{\circ} \mathrm{C}$ for 30 s, and $72^{\circ} \mathrm{C}$ for $1 \mathrm{~min}$, with a final extension at $72^{\circ} \mathrm{C}$ for $5 \mathrm{~min}$. The relative expression of each gene was determined by the $2^{-\Delta \Delta \mathrm{CT}}$ method (Livak and Schmittgen, 2001) using $\beta$-actin expression as a reference.

Table 1. Primers used in this study

\begin{tabular}{cc}
\hline Primer name & Sequence (5'-3') \\
\hline $\begin{array}{c}\text { for qRT-PCR } \\
\text { amplification : }\end{array}$ & \\
RbCTL3-F & CGCTGTTTCCTGTTCCAGTT \\
RbCTL3-R & TTATGCGAGTTAGCCGTTT \\
& \\
Bactin F & GGACACGGAAAGGATTGACA \\
B-actin R & CGGAATTAACCAGACAAATC \\
\hline
\end{tabular}

Results and Discussion

C-type lectins are present in most organisms. They bind to specific carbohydrates and are important in nonself-recognition and clearing invading microorganisms (Dodd and Drickmer, 2001; Vasta et al., 2004). In this study, a C-type lectin (RbCTL) was isolated from rock bream, Oplegnathus fasciatus using EST analysis techniques. The RbCTL cDNA comprised 729 bp containing a $492 \mathrm{bp}$ open reading frame (ORF), encoding a putative 164 amino acid protein with a predicted molecular mass of $17.9 \mathrm{kDa}$ (accession no. AB618052). The cDNA of RbCTL also contained a 5' untranslated region (UTR) of 37 nucleotides, a 3'-UTR of 200 nucleotides including a stop codon (TAA), a putative polyadenylation consensus signal (AATAAA) and a poly (A) tail (Fig. 1). The deduced Rb-CTL 3 amino acid sequence of contained a putative signal peptide of 20 residues and a single C-type CRD. Several important signatures of the C-type lectin family were found in RbCTL. The calculated molecular mass of the mature $\mathrm{Rb}-\mathrm{CTL} 3$ protein was $17.9 \mathrm{kDa}$ with a theoretical isoelectric point of 6.69. RbCTL contains a C-type lectin (CTL) or carbohydrate-recognition domain (CLECT) similar to CRD. An EPN motif was found in the CRD of RbCTL, which differed from the highly conserved EPN motif. The EPN motif has also been identified in C-type lectin receptors SCLRA and SCLRB (Soanes et al., 2004), CfLec-1 and Cflec-2 (Wang et al., 2007; Zheng et al., 2008). The carbohydrate specificity in $\mathrm{RbCTL}$ is possibly determined by the orientation of hydrogen bond donors and acceptors, and its overall structure, which requires further investigation. 


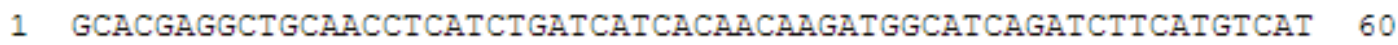

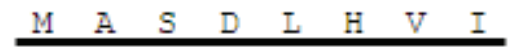

61 TGTGGTCCTCTGTTTGACCAGTGGACTGTGGATCGCAACTGCGACATGTGGAGAACAATC

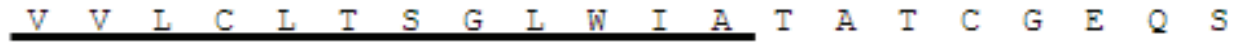

121 AGGTGATTGTGGCGCAACCTGCCCTACTGGTTGGACTCAATTTGGCAGTCGCTGTTTCCT

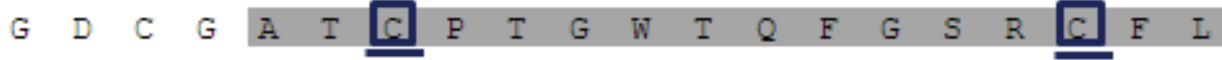

181 GTTCCAGTTACGTCCAATGGACTGGGCTGATGCAGAGCGTTTCTGCACTTCTCTCGGTGG

$$
\begin{array}{lllllllllllllllllllll}
F & Q & L & R & P & M & D & \text { W } & A & D & A & E & R & F & C & T & S & L & G & G
\end{array}
$$

241 AAATCTGGCTTCCCTCCAAACTGCAGGCGAGTACGCCTTCATCAGACAGTTGATTTACAA

421 CAACTCTGCAGGAGGAGAAGCTTGCATGGAGATCAATCTTTTTGGACGAGATTTTGTCAA $\begin{array}{lllllllllllllllllllllll}N & S & A & G & G & E & A & C & M & E & I & N & L & F & G & R & D & F & V & N\end{array}$

\section{AAAAAAAAA 729}

Fig. 1. The cDNA and deduced amino acid sequences of Rb-CTL 3 from the rock bream, Oplegnathus fasciatus. Amino acid residues in the mature protein are assigned a positive number, and those in the single peptide are assigned negative number. The signal peptide sequence is underlined. Four conserved cysteine residues (blue box) that define the C-type lectin domain (CLECT) are shaded gray, and two extra cysteine residues are underlined and bboxed in blue. The EPN motif important for determining ligand-binding specificity is in bold red letters. The polyadenylation signal sequence AATAA and poly (A) tail are in bold.

Database searches with the deduced RbCTL amino acid sequence showed that RbCTL3 was $29.4 \%$ similar to the C-type lectin from Oncorhynchus mykiss (accession no. NP_001117900). The RbCTL CRD was aligned with other fish C-type lectins containing a long form CRD with six conserved cysteine residues (Fig. 2). Most C-type lectins have an EPD or EPN motif, predicted to be important for $\mathrm{Ca}^{2+} /$ carbohydrate-binding. 
Four disulfide-bonded cysteine residues defining CRD and two additional cysteine residues at the amino terminus were completely conserved in RbCTL (Fig. 2).

Mammalian C-type lectins are calcium-dependent.

For example, the mammalian mannose-binding protein (MBP) (Weis et al., 1992; Weis et al., 1991), macrophage mannose receptor (Mullin et al., 1997) and selectins (Graves et al., 1994) require calcium for their activity.
In shellfish, the C-type lectin of CLHd from abalone, Haliotis asinine, showed calcium-dependent activities. However some C-type lectins do not require calcium to function such as OLABL, a C-type lectin from shishamo smelt, Osmerus (Sprinchus) lanceolatus egg. Several C-type lectins also do not require calcium for their binding activity, but require calcium for agglutination activity (Yu et al., 2007).

Rock bream
Shisahmo
Sablefish
Atlantic salmon 1
Atlantic salmon 2
Sea urchin
barramundi perch
mottled moray
northern pike
rainbow trout
yellow perch
yellow-edged moray
zebrafish
Rock bream
Shisahmo
Sablefish
Atlantic salmon 1
Atlantic salmon 2
Sea urchin
barramundi perch
mottled moray
northern pike
rainbow trout
yellow perch
yellow-edged moray
zebrafish
Rock bream
Shishamo
Sablefish
Atlantic salmon 1
Atlantic salmon 2
Sea urchin
barramundi perch
mottled moray
northern pike
rainbow trout
yellow perch
yellow-edged moray
zebrafish

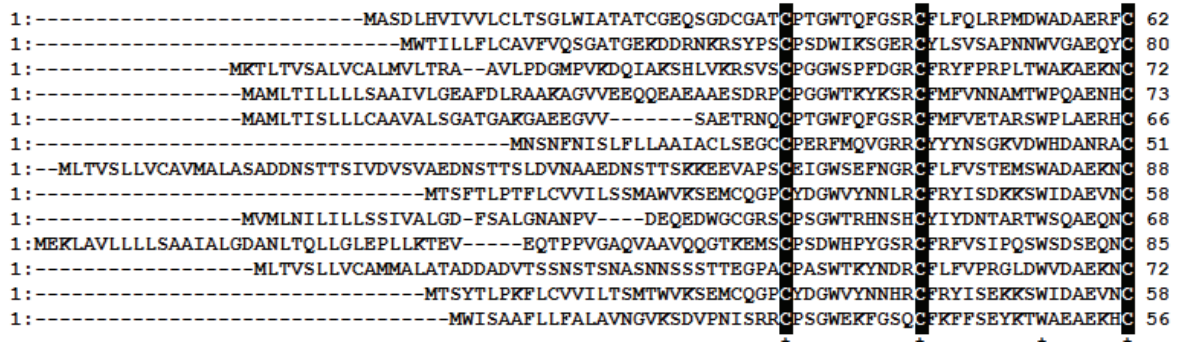

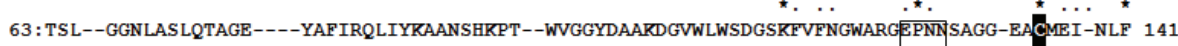
81: LRQ--GANLASVHSFSE----YTFLQQLVGSESNGHPVT--WIGGTDAFQDRVWFWSDGSSFDYAAWAAGEPNNYGGRREPCIEM-NWG 139 73: ESM--GGNLASVHNILE----YHEIORLILSGSHEHRET--WVGGSDAOEEKOWFWADGTPFRYVNWCDR PNN SRGR-QHCLQV-NHR 150 84 : LSF--QANLASIKDCVE----NYNLQQLVLRNTGQHQPT--WIGGFNSVQNKLWFWSDGSKFDYQGWGQGEPNIYGGN-EHCLQM-NAG 151 67 :VSL--GANLASVHSSAD----DQFLQEVVGSKTGGFSTT--WIGGFDAVQDRLWFWSDGSEFDYQNWKKGEPNASGGR-EPCIVI-NWG 144 52 : QRL--GAHLVSIHNAEDSREVYALWKS LVDADRRDDRDAAYWIGLNDDRIEGFFEWSDGTRLGYSLWQRGEPNNTNGG-EDCVAPRNDG 137 89: LLK--KGHLASVHNEEE----YKHIOAVVNAHTGGHPTT--WVGGSDCOKEGIWLWSDGSGFEFDSWCEGEPDNYVGA-ESCLQI-NAN 166 59 :VSI--GGNLASECCEED----DNFMIRELQ-KSAHGDGPF--WIGLTDLHKENVWIWSDGTHIRYTHWNDGEPNNLGEE--HCVHT-NWG 134 69 :VYL--GGNLVSIHNDGE----NEAVKDVVFKATNSYPLT--WIGGSD LYKT'KVWFWSDGTKFGYSNWASGEPNAGGGT-EHCGQI-NYP 146 86: LAL--GGNLASVNNLLE----YQFMQALTKNTNGHLPDT--WIGGFDAVKEGLWMWSDGSRFDYTNWNTGEPNNAGEG-EDCLQM-NAA 163 73: OSS--KGNLASVHSVEE----YOFIOMIIKOQTHANPMT--WIGGQDALKNNVWFWSDGRPFYFTFWCAGEPNNGSGN-QHCIEM-NFG 150 59 :VSI--GGNLASDCCEED----SPFIKE LQ-KAEKGEEPF--WIGLTDCHKENIWIWSDGTHVRYTHCNDGEPNN LGEE---ECVHT-IWG 134 57 :VDL--GGNLASIQSDIT----HNFLIAYLKRQEKGITRT--WIGAHDATQADIWFWSDGSKFEYSAWHSGEPNNGGNA-ERCAEM-GFG 134 $\ldots{ }^{\star} \cdot{ }^{\star}$

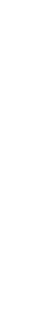

(2)

Fig. 2. Multiple-sequence alignment of the Rb-CTL 3 CRD with CRDs of 11 other fish C-type lectins. They were aligned using ClustalX. Conserved cysteine residues that define the C-type lectin domain are boxed and indicated by asterisks. The cysteine residues are shaded black and the EPN motifs are boxed. The lectins used in the alignment are as follows : Salmo salar ACI67625, Esox lucius ACO13755, Oncorhynchus mykiss NP 001117900, Danio rerio XP 002660413, Strongylocentrotus stephensii ACN12988, Gymnothorax flavimarginatus BAC78901, Echidna delicatula BAD83812, Perca flavescens AC082031, Anoplopoma fimbria ACQ58623, Spirinchus lanceolatus BAE45334, Lates calcarifer ABV66064. 


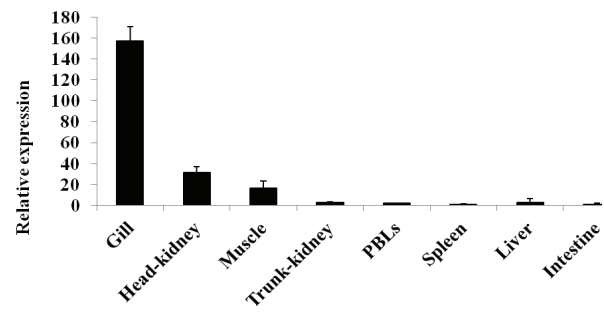

Fig. 3. Quantitative real-time PCR analysis of the expression patterns of rock bream C-type lectin 3 showing the relative levels of RbCTL3 mRNA in different tissues.

Using quantitative real-time PCR analysis in healthy rock bream, RbCTL mRNA was highly expressed in gill tissue (Fig. 3). Gills are respiratory organ in vertebrates and invertebrates, and are exposed in aquatic environments. In fish, gills are important in host defense against microorganism invasion by various mechanisms. The high level of expression of RbCTL in gill tissue suggests that may be involved in the innate immune response. Similar gene expression patterns have been observed for other immune-related genes in fish (Williams et al., 2009). Additionally, C-type lectin mRNA expression patterns have been reported in previous. The rock bream lectin (lily-type lectin) was highly expressed in gill tissue (Arockiaraj and Bhassu, 2011).

Lymphocyte mitogens, such as lipopolysaccharides (LPS) and concanavalin A (Con A), have been used to stimulate immunity-related genes (Ulmer et al., 2000; Wang et al., 2005). LPS, an essential component of endotoxin, can cause heterophil granulocytes and monocytes/macrophages to release many inflammatory cytokines, which can have toxic effects on cells (Qin et al., 2009). The Con A activation system has been to analyse molecular determinants of fish leukocyte proliferation (Graham and Secombes, 1988; Yin et al., 1999). Phorbol myristate acetate (PMA) has been used with Con A or LPS as a mitogen (Johnson et al., 1987; Takeshita et al., 1988; Murphy and Norton, 1993). PMA, however, when used alone, is not mitogenic and does not cause proliferation (Kumagai et al., 1988). Polyriboinosinic polyribocytidylic acid (pIC) is a synthetic dsRNA widely used to study the immune response to virus infection. It is a potent inducer of type I interferon genes in fish that is known to induce some, but not all, of the stimulatory effects of viral dsRNA in higher vertebrates (Robertson, 2006; Huang et al., 2006).

In the mitogen-stimulated PBL expression analysis, we observed the induction of RbCTL expression 1-24 $\mathrm{h}$ after the PBLs were stimulated with LPS, Con A/PMA or poly I:C. The RbCTL mRNA levels appeared to peak with LPS and Con A/PMA at $24 \mathrm{~h}$ post-stimulation, however, with poly I:C mRNA increased $1 \mathrm{~h}$ post-stimulation and decreased at 3-24 h (Fig. 4). The poly I:C stimulated leukocytes were significantly induced compared with the control and LPS and Con A/PMA stimulated leukocytes. These results suggested that RbCTL play a important role in host's first line of defence against invasion of pathogens.

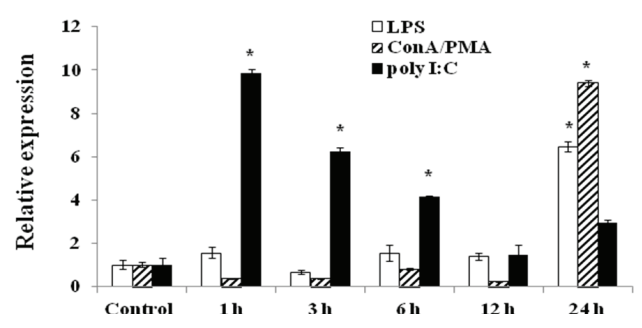

Fig. 4. Quantitative real-time PCR analysis of the expression of C-type lectin 3 genes in rock bream leukocytes stimulated with LPS $(500 \mu \mathrm{g} / \mathrm{mL})$, Con A $(70 \mu \mathrm{g} / \mathrm{mL}) / P M A(0.35 \mu \mathrm{g} / \mathrm{mL})$ or Poly I:C $(5 \mu \mathrm{g} / \mathrm{mL})$ at $1,3,6,12$ and $24 \mathrm{~h}$. 
In this study, a C-type lectin was successfully cloned from the rock bream, Oplegnathus fasciatus, using ESTs analysis. RbCTL gene expression might be regulated by bacterial or viral challenges via, binding activity with various bacteria and virus pathogens. RbCTL could be an important molecule involved in pattern recognition and pathogen elimination in the innate immunity of the rock bream.

\section{Acknowledgements}

This work was funded by a grant from the National Fisheries Research and Development Institute (RP-2011-AQ-018).

\section{References}

Arockiaraj, J., Bhassu, S.: Molecular characterization and expression analysis of lily type lectin-1 (OfLTL-1) in rock bream (Oplegnathus fasciatus). Fish Shellfish Immunol. (Article in press).

Dodd, R.B., Drickamer, K.,: Lectin-like proteins in model organisms: implications for evolution of carbohydrate-binding activity. Glycobiol., 11: 71R-9R, 2001.

Drickamer, K.: C-type lectin-like domains. Curr. Opin. Struct. Biol., 9: 585-590, 1999.

Fujiki, K., Bayne, C.J., Shin, D.H., Nakao, M., Yano, T.: Molecular cloning of carp (Cyprinus carpio) C-type lectin and pentraxin by use of suppression subtractive hybridisation. Fish Shellfish Immunol., 11: 275-279, 2001.

Fujita, T., Matsushita, M., Endo, Y.: The lectin-complement pathway-its role in innate immunity and evolution.
Immunol. Rev., 198: 185-202, 2004.

Gish, W., David, J.S.: Identification of protein coding regions by database similarity search. Nature Genetics., 3: 266-272, 1993.

Graham, S., Secombes, C.J., 1988. The production of a macrophage-activating factor from rainbow trout Salmo gairdneri leucocytes. Immunology 65, 293-297.

Graves, B.J., Crowther, R.L., Chandran, C., Rumberger, J.M., Li, S., Huang, K.S., Preskiy, D.H., Familletti, P.C., Wolitzky, B.A., Burns, D.K.: Insight into E-selectin/ligand interaction from the crystal structure and mutagenesis of the lec/EGF domains. Nature., 367: 532-538, 1994.

Holmskov, U., Thiel, S., Jensenius, J.C.: Collections and ficolins: humoral lectins of the innate immune defense. Annu. Rev. Immunol., 21: 547-578, 2003.

Honda, S., Kashiwagi, M., Miyamoto, K., Takei, Y., Hirose, S.: Multiplicity, structures, and endocrine and exocrine natures of eel fucose-binding lectins. J. Biol. Chem., 275: 33151-33157, 2000.

Huang, C.C., Duffy, K.E., San Mateo, L.R., Amegadzie, B.Y., Sarisky, R.T., Mbow, M.L., 2006. A pathway analysis of poly(I:C)-induced global gene expression change in human peripheral blood mononuclear cells. Physiol Genom. 26, 125-133.

Janeway, C.A. Jr., Medzhitov, R.: Innate immune recognition. Annu. Rev. Immunol., 20: 197-216, 2002.

Johnson, M.D., Housey, G.M., Kirschmeier, P.T., Weinstein, I.B., 1987. Molecular cloning of gene sequences regulated by tumor promoters and mitogens through protein kinase C. Mol. Cell Biol. 7, 2821-2829. Kim, J.W., Park, H.J., Baeck, G.W., Park, C.I.: Preliminary 
EST analysis of immune-relevant genes from the liver of LPS-stimulated rock bream Oplegnathus fasciatus. J. Fish pathol., 23: 229-238, 2010.

Konstantina, N., Ioannis, K.Z.: Molecular cloning and characterization of two homologues of mannose-binding lectin in rainbow trout. Fish Shellfish Immunol., 21: 305-314, 2006.

Kumagai, N., Benedict, S.H., Mills, G.B., Gelfand, E.W., 1988. Induction of competence and progression signals in human $\mathrm{T}$ lymphocytes by phorbol esters and calcium ionophores. J. Cell Physiol. 137, 329-336.

Livak, K.J., Schmittgen, T.D.: Analysis of relative gene expression data using real-time quantitative PCR and the 2-LCT method. Methods , 25:402-8, 2001.

McGreal, E.P.: Martinez-Pomares L, Gordon S. Divergent roles for C-type lectins expressed by cells of the innate immune system. Mol. Immunol., 41: 1109-1121, 2004.

Mullin, N.P., Hitchen, P.G., Taylor, M.E.: Mechanisms of $\mathrm{Ca}^{2+}$ and monosaccharide binding to a C-type carbohydrate-recognition domain of the macrophage mannose receptor. J. Biol. Chem., 272: 5668-5681, 1997.

Murphy, J.J., Norton, J.D., 1993. Phorbol ester induction of early response gene expression in lymphocytic leukemia and normal human B cells. Leuk. Res. 17, 657-662.

Oh, D.J., Kim, J.Y., Lee, J.A., Yoon, W.J., Park, S.Y., Jung, Y.H.: Complete mitochondrial genome of the rock bream Oplegnathus fasciatus (Perciformes, Oplegnathidae) with phylogenetic considerations. Gene., 392: 174-180, 2007.
Okamoto, M., Tsutsui, S., Tasumi, S., Suetake, H., Kikuchi, K., Suzuki, Y.: Tandem repeat L-rhamnose-binding lectin from the skin mucus of ponyfish, Leiognathus nuchalis. Biochem. Biophys. Res. Commun., 333: 463-469, 2005.

Ottinger, C.A., Johnson, S.C., Ewart, K.V., Brown, L.L., Ross, N.W.: Enhancement of anti- Aeromonas salmonicida activity in Atlantic salmon (Salmo salar) macrophages by a mannose-binding lectin. Comp. Biochem. Physiol. C. Pharmacol. Toxicol. Endocrinol., 123: 53-59, 1999.

Ourth, D.D., Narra, M.B., Simco, B.A.: Comparative study of mannose-binding C-type lectin isolated from channel catfish (Ictalurus punctatus) and blue catfish (Ictalurus furcatus). Fish Shellfish Immunol., 23: 1152-1160, 2007.

Park, C.I., Kurobe, T., Hirono, I., Aoki, T.: Cloning and characterization of cDNAs for two distinct tumor necrosis factor receptor superfamily genes from Japanese flounder Paralichthys olivaceus. Dev. Comp. Immunol., 27: 365-375, 2003.

Qin, L.H., Wang, R.G., Li, S., Li, C.M., 2009. Differentially gene expression profile related to inflammation in endometrial cells induce by lipopolysaccharide. J. Reprod. Contracep. 20, 27-34.

Robertson, B., 2006. The interferon system of teleost fish. Fish Shellfish Immunol. 20, 172-191.

Soanes, K.H., Figuereido, K., Richards, R.C., Mattatall, N.R., Ewart, K.V.: Sequence and expression of C-type lectin receptors in Atlantic salmon (Salmo salar). Immunogenetics ., 56: 572-584, 2004.

Takeshita, T., Goto, Y., Nakamura, M., Fujii, M., Iwami, M., Hinuma, Y. Sugamura, K. 1988. Phorbol esters 
can persistently replace interleukin-2 (IL-2) for the growth of a human IL-2-dependent T-cell line. J. Cell Physiol. 136, 319-325.

Tasumi, S., Ohira, T., Kawazoe, I., Suetake, H., Suzuki, Y., Aida, K.: Primary structure and characteristics of a lectin from skin mucus of the Japanese eel Anguilla japonica. J. Biol. Chem., 277: 2730527311, 2002.

Thompson, J.D., Higgis, D.G., Gibson, T.J.: CLUSTAL $\mathrm{W}$ : improving the sensitivity of progressive multiple sequence alignment through sequence weighting, position specific gap penalties and weight matrix choice. Nucleic Acids Res., 22: 4673-4680, 1994.

Tsutsui, S., Iwamoto, K., Nakamura, O., Watanabe, T.: Yeast binding C-type lectin with opsonic activity from conger eel (Conger myriaster) skin mucus. Mol. Immunol., 44: 691-702, 2007.

Ulmer, A.J., Flad, H., Rietschel, T., Mattern, T., 2000. Induction of proliferation and cytokine production in human $\mathrm{T}$ lymphocytes by lipopolysaccharide (LPS). Toxicology 152, 37-45.

Vasta, G.R., Ahmed, H., Odom, E.W.: Structural and functional diversity of lectin repertoires in invertebrates, protochordates and ectothermic vertebrates. Curr. Opin. Struct. Biol., 14: 617-630, 2004.

Vasta, G.R., Ahmed, H., Du, S., Henrikson, D.: Galectins in teleost fish: Zebrafish (Danio rerio) as a model species to address their biological roles in development and innate immunity. Glycoconj. J., 21: 503-521, 2004.

Vitved, L., Holmskov, U., Koch, C., Teisner, B., Hansen, S., Salomonsen, J., Skjødt, K.: The homologue of mannose-binding lectin in the carp family
Cyprinidae is expressed at high level in spleen, and the deduced primary structure predicts affinity for galactose. Immunogenetics ., 51: 955-964, 2000.

Wang, H., Song, L., Li, C., Zhao, J., Zhang, H., Ni, D., $\mathrm{Xu}, \mathrm{W} .:$ Cloning and characterization of a novel C-type lectin from Zhikong scallop, Chamys farreri. Mol. Immunol., 44: 722-731, 2007.

Wang, Y., Gao, B., Tsan, M.F., 2005. Induction of cytokines by heat shock proteins and concanavalin A in murine splenocytes. Cytokine 32, 149-154.

Weis, W.I., Drickamer, K., Hendrickson, W.A.: Structure of a C-type mannose- binding protein complexed with an oligosaccharide. Nature., 360: 127-134, 1992.

Weis, W.I., Kahn, R., Fourme, R., Drickamer, K., Hendrickson, W.A.: Structure of the calciumdependent lectin domain from a ratmannosebinding protein determined by MAD phasing. Science., 254: 1608-1615, 1991.

Williams, H.R., Macey, B.M., Burnett, L.E., Burnett, K.G.: Differential localization and bacteriostasis of Vibrio campbellii among tissues of the Eastern oyster, crassostrea virginica. Dev. Comp. Immunol., 33: 592-600, 2009.

Yin, Z., He, J.Y., Gong, Z., Lam, T.J., Sin, Y.M., 1999. Identification of differentially expressed genes in con A-activated carp (Cyprinus carpio L.) leucocytes. Comp. Biochem. Physiol. Part B 124, 41-50.

Yousif, A.N., Albright, L.J., Evelyn, T.P.T.: Purification and characterization of a galactose-specific lectin from the eggs of coho salmon (Oncorhynchus kisutch) and its interaction with bacterial fish pathogens. Dis. Aquat. Org., 20: 127-136, 1994. 
Yu, Y.H., Yu, Y.C., Huang, H.Q., Feng, K.X., Pan, M.M., Yuan, S.C., Huang, S.H., Wu, T., Guo, L., Dong, M.L., Chen, S.W., Xu, A.L.: A shortform Ctype lectin from Amphioxus acts as a direct microbial killing protein via interaction with peptidoglycan and glucan. J. Immunol., 179: 8425-8434, 2007.

Zhang, H., Robison, B., Thorgaard, G.H., Ristow, S.S.: Cloning, mapping and genomic organization of a fish C-type lectin gene from homozygous clones of rainbow trout (Oncorhynchus mykiss). Biochim. Biophys. Acta., 1494: 14-22, 2000.
Zheng, P.L., Wang, H., Zhao, J.M., Song, L.S., Qiu, L.M., Dong, C.H., Wang, B., Gai, Y.C., Mu, C.K., Li, C.H., Ni, D.J., Xing, K.Z.: A lectin (CfLec-2) aggregating Staphylococcus haemolyticus from scallop Chlamys farreri. Fish Shellfish Immunol., 24: 286-293, 2008.

Manuscript Received : October 17, 2011

Revised : January 2, 2012

Accepted : January 5, 2012 